\title{
Endoscope-connected water pump with high flow rates improves the unsedated colonoscopy performance by water immersion method
}

This article was published in the following Dove Press journal:

Clinical and Experimental Gastroenterology

\author{
Putut Bayupurnama' \\ Neneng Ratnasari' \\ Fahmi Indrarti' \\ Catharina Triwikatmani' \\ Sutanto Maduseno' \\ Siti Nurdjanah' \\ Felix W Leung ${ }^{2}$ \\ 'Division of Gastroenterology and \\ Hepatology, Department of Internal \\ Medicine, Faculty of Medicine, Sardjito \\ General Hospital, Gadjah Mada \\ University, Yogyakarta, Indonesia; \\ ${ }^{2}$ Sepulveda Ambulatory Care Center, \\ Veterans Affairs Greater Los Angeles \\ Healthcare System and David Geffen \\ School of Medicine at UCLA, Los \\ Angeles, CA, USA
}

Objectives: The aim of this study was to determine if different water pump flow rates influence the insertion time of water immersion method in unsedated patients. We tested the hypothesis that high flow rate (HFR) is more effective than low flow rate (LFR) in facilitating insertion. Clinical registration number: NCT01869296.

Methods: Consecutive symptomatic patients without prior abdominal surgery were consented and enrolled. They were randomized to an HFR $(10.4 \mathrm{~mL} / \mathrm{s})$ or LFR $(1.7 \mathrm{~mL} / \mathrm{s})$ group. The patients were not informed about the flow rate of the water pump (single blinded). Patients underwent unsedated colonoscopy examination with standard colonoscope. Demographic and procedural parameters were recorded. Data were analyzed with Student's $t$-test or Chi-square test as appropriate.

Results: A total of 132 patients (66 in HFR and 66 in LFR group) were recruited. The HFR group showed significantly shorter cecal intubation time (12.5 $\pm 6.2 \mathrm{~min}$ in HFR vs $16.3 \pm 7.3$ min in LFR, $p=0.004)$, shorter time to pass rectosigmoid (3.6 $\pm 2.2 \mathrm{~min}$ in HFR vs $6.2 \pm 4.6 \mathrm{~min}$ in LFR, $p<0.001)$, and lower pain score $(4.2 \pm 2.8$ in HFR vs $5.3 \pm 2.6$ in LFR, $p=0.024)$. The cecal intubation rate was not significantly different ( $87.9 \%$ in HFR vs $80.3 \%$ in LFR, $p=0.34$ ), and 29 (14 in HFR and 15 in LFR) patients with signs of colon redundancy were successfully intubated to the cecum after repeated loop reduction and position changes.

Conclusion: Compared to LFR, HFR of the water infusion pump significantly reduced colonoscopy insertion time and pain score in unsedated patients. Significantly shorter time to pass the rectosigmoid appeared to play a contributory role

Keywords: colonoscopy, unsedated, water pump, flow rates, cecal intubation

\section{Introduction}

Water method colonoscopy examination in unsedated patients is an important and useful method to examine and establish the diagnosis of various diseases in the colon because it reduces discomfort and enhances willingness to repeat and also increases colonic polyp detection compared with usual air insufflation method. ${ }^{1-4}$

This examination is usually performed using two different methods: water immersion and water exchange. In the water immersion method, the water is infused into the colon beginning with the scope inserted into the anus during examination until the scope reaches the cecum. The water is evacuated during colonoscope withdrawal. In the water exchange method, the water is evacuated during colonoscope advancement until the cecum is reached. The air pump of the endoscopy machine is turned off during examination in both procedures; however, some investigators allow some air insufflation during insertion with water immersion method. ${ }^{5}$
Correspondence: Putut Bayupurnama Division of Gastroenterology and Hepatology, Department of Internal Medicine, Faculty of Medicine, Sardjito General Hospital, Gadjah Mada University, Jl Kesehatan number I, Sekip, Yogyakarta 55284, Indonesia

Tel +62 274553119

Email pututby@yahoo.com 
Colonoscopy is successful when the tip of the scope reaches the cecum and the ileocecal valve and/or appendix orifice are observed. Studies showed that replacing the air insufflation with water infusion into colon starting at the beginning of the examination increased the success rate of cecal intubation and reduced the abdominal pain symptoms during colonoscopy examination., ${ }^{2,3}$ Our earlier unsedated colonoscopy study showed that the water immersion method with high-flow rate (HFR; $10.4 \mathrm{~mL} / \mathrm{s}$ ) endoscopy pump had similar cecal intubation rate but lower discomfort score compared with conventional air insufflation method. ${ }^{3}$ Removal of the water during withdrawal took time, and we wanted to find out if a small volume and low flow rate (LFR) will achieve the same effect during insertion. Comparison of water pumps with different water flow rates may also provide an indirect assessment of the pressure effect of water in water immersion colonoscopy examination..$^{5}$ The aim of this study was to determine if different water pump flow rates influence the insertion time of water immersion method in unsedated patients. We chose water immersion method rather than water exchange for this evaluation because water immersion, characterized by suction removal of the infused water predominantly during withdrawal, is more appropriate for assessing the direct effect of water flow rates; simultaneous suction of water with water exchange alters the impact of the infused water. The result of this study will assist the colonoscopist in deciding which endoscopy water pump should be used for successful water immersion colonoscopy examination.

\section{Methods}

\section{Design}

This study was a randomized controlled trial that compared the HFR vs LFR endoscope-connected water pump in water immersion method of colonoscopy. The protocol was approved by Biomedical Research Ethics Commission of the Faculty of Medicine, Gadjah Mada University, Yogyakarta, Indonesia, and registered in ClinicalTrial.gov (NCT01869296). All patients signed written informed consent for enrollment.

\section{Subjects}

This study was conducted between June 2013 and June 2015. Patients were $>18$ years old with indication for colonoscopy, such as chronic diarrhea, chronic constipation, hematochezia, chronic lower abdominal pain, positive fecal occult blood test, and other change of bowel habits indicative of need for diagnostic colonoscopy examination. The patients were seen in the hospital clinic or were hospitalized in Sardjito General Hospital, Yogyakarta, Indonesia, and several patients were from the author's (PB) private clinic. We excluded patients who refused to participate, those with obstructive lesion in the colon distal of the cecum, history of colon resection, severe cardiac disorders (such as acute myocardial infarction, unstable angina, malignant arrhythmia, and moderateto-severe congestive heart failure), or fecal obstruction (whatever may be the cause) so that it is impossible to pass the scope through the obstructed segment, those who were hemodynamically unstable, and those with inability to communicate well that might influence the visual analog scale (VAS) score marking. Education level was defined as high (college or university) or low (senior high school education or lower). Sodium phosphosoda was used as purgative for bowel preparation.

\section{Colonoscopy examination procedure}

Eligible patients in the hospital clinics or wards were offered unsedated colonoscopy examination with water immersion method. The principal investigator explained the study, the colonoscopy procedure, the various symptoms that might be felt during examination, and the possible adverse events and medical effort to prevent them. Patients who signed the informed consent were included in the study.

Enrolled patients were sent to the endoscopy room, and colonoscopies were performed by PB. Patients lied in the left lateral position with right hip and knee flexed and left leg straight. When PB was about to start the single-handed colonoscopy examination, the blinded observer opened the sealed envelope with the code enclosed. A standard colonoscope (12.8 $\mathrm{mm}$ in diameter) was used in this study. Patients were asked to change position when it was needed. Oximetry, cardiac rhythm, and blood pressure were monitored during examinations. Patients were blinded by camouflage of the endoscopy reporting system monitor and endoscopyconnected water pump and were not informed about the method before, during, or immediately after the examination. The colonoscopist technically could not be blinded because of different endoscope-connected water channels. The study method included water immersion colonoscopy using LFR endoscopy water pump (1.7 mL/s; JW-2 FujiFilm endoscopy water pump). The control method included water immersion colonoscopy with HFR endoscopy water pump (10.4 mL/s; Pauldrach endoscopy water jet pump). Water was infused as needed by the endoscopy-connected water pump through the adaptor on the colonoscope based on judgment of the endoscopist. Usual air insufflation was applied during colonoscope withdrawal to facilitate mucosal examination. 


\section{Water immersion method colonoscopy}

This colonoscopy procedure was mostly similar to our earlier study. ${ }^{3}$ First, the endoscopy machine's air pump was turned off before the colonoscopy examination started. The tip of colonoscope was inserted and oriented toward the slit-like lumen ahead, and the water was infused concurrently to open the lumen. The colonoscope was advanced by a series of motions of the colonoscope shaft to the expected lumen, and the water was intermittently infused as needed. Colonic lumen with residual air was bypassed, and the obstructing feces were suctioned when encountered.

Episodes of suction were performed as needed in the difficult colonic curve. Cecal intubation was suggested when the endoscopic image movement on the monitor was appropriate with the palpation of the right-lower quadrant of the abdomen, or visualization of appendix orifice under water. The air pump was turned on when the cecum successfully intubated and then distended the cecum with the air to confirm the appearance of the ileocecal valve and the appendix orifice. The aspiration of most of the water and colonic mucosal examination were carried out concomitantly during withdrawal. Prior to the start of the trial, PB had performed at least 400 scheduled water immersion method colonoscopies in unsedated patients.

\section{Primary outcome variable}

The primary outcome was cecal intubation time defined as the time needed to insert the colonoscope from the anus to the cecum.

\section{Secondary outcome variables}

The secondary outcomes included time to pass the rectosigmoid, and abdominal discomfort score which was defined as the level of abdominal discomfort experienced by the patient during colonoscopy and reported to a blinded observer immediately after end of examination and was measured on a linear VAS: $0=$ none, $10=$ most severe. Additional secondary outcomes included willingness to repeat colonoscopy, causes of unsuccessful cecal intubation, position change, and diagnostic findings. The cecal intubation rate was defined as successful insertion of the colonoscope to the cecum with the tip of the colonoscope touching the floor of the cecum and visualization of the medial cecal wall between the ileocecal valve and/or appendix orifice.

\section{Sample size estimation}

In one published study, we reported that the cecal insertion time with water immersion was $11.9 \pm 5.5 \mathrm{~min} .{ }^{3} \mathrm{In}$ the current study, we postulated the difference between HFR and LFR cecal intubation time to be at least 0.5 standard deviation (SD) unit (2.75 min). Sample size (n) per group needed to detect a statistically significant difference between two groups at a $5 \%$ alpha error level with $80 \%$ power would be $64{ }^{6}$

\section{Statistical analysis}

Data were analyzed with SPSS statistical software. Descriptive statistic was used to evaluate the distribution of each variable. Data were presented as frequency counts and percentage of total, mean $\pm \mathrm{SD}$ and median (interquantile range). Chi-square test, Mann-Whitney $U$-test, and Student's $t$-test were used to evaluate the independent samples, with $p<0.05$ considered to be significant.

\section{Results}

Figure 1 shows that 132 patients were randomized into HFR or LFR group. LFR group showed higher failure rate than the HFR group. Chronic diarrhea and hematochezia were the main indications of colonoscopy in this study (Table 1), and Kolmogorov-Smirnov test showed normal distribution of discomfort score and duration of colonoscopy.

\section{Primary outcome}

Cecal intubation time was significantly faster in the HFR group with about $3.8 \mathrm{~min}$ difference (HFR vs LFR: 12.5 \pm 6.2 $\min$ vs $16.3 \pm 7.3 \mathrm{~min} ; p=0.004$ ) (Table 2 ).

\section{Secondary outcomes}

Table 2 shows that in the HFR group, cannulation of the rectosigmoid was significantly faster than in the LFR group with about $2.6 \mathrm{~min}$ difference (HFR vs LFR: $3.6 \pm 2.2 \mathrm{~min}$ vs $6.2 \pm 4.6 \mathrm{~min} ; p<0.001$ ). The pain score (VAS) was significantly lower in the HFR group ( $p=0.024)$. The cannulation time of the rectosigmoid was faster in patients with redundant colon in the HFR group $(p=0.01)$. Patients without constipation in HFR group also had significantly faster rectosigmoid cannulation and cecal intubation time. Cecal intubation rate was not significantly different.

\section{Discussion}

Our study showed that the HFR of endoscope water pump speeded up the cannulation of the rectosigmoid, and allowed faster cecal intubation and reduced the patient discomfort. Current water method colonoscopies are water immersion and water exchange colonoscopies. Colon deformations that should be overcome during colonoscopy include colon stretching, ligament stretching, and peritoneal stretching 


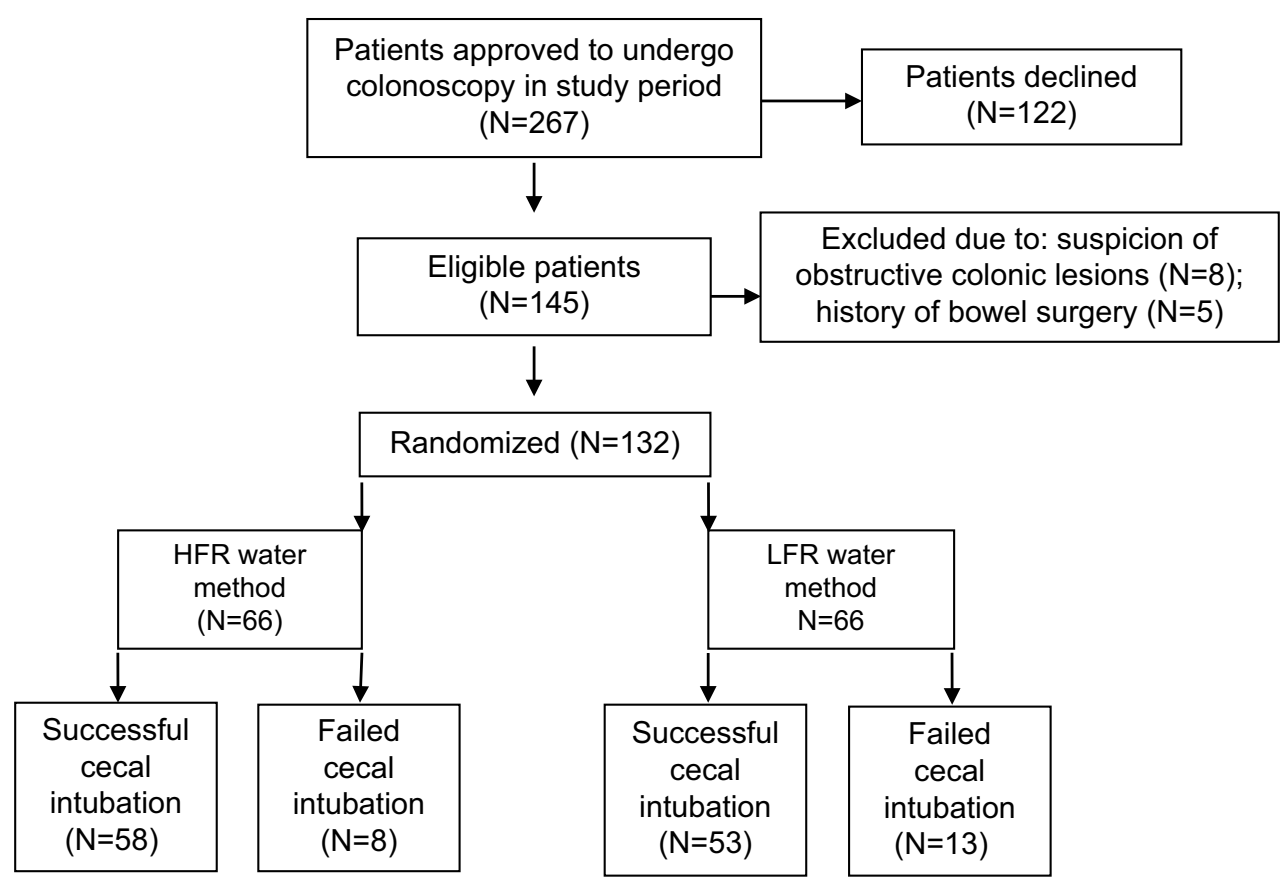

Figure I Flow chart of patient enrollment.

Abbreviations: HFR, high flow rate; LFR, low flow rate.

Table I Demographic and basic characteristic variables

\begin{tabular}{llll}
\hline Variables & $\begin{array}{l}\text { High flow } \\
\text { rates }\end{array}$ & $\begin{array}{l}\text { Low flow } \\
\text { rates }\end{array}$ & p-value \\
\hline Patients, $\mathrm{n}$ & 66 & 66 & \\
$\begin{array}{l}\text { Gender (male/female), } \mathrm{n} \\
\text { Age (years), mean } \pm \text { SD }\end{array}$ & $44 / 22$ & $34 / 32$ & 0.11 \\
$\begin{array}{l}\text { Colonoscopy indications, } \mathrm{n} \\
\quad \text { Chronic diarrhea }\end{array}$ & $50.1 \pm 14.9$ & $50.1 \pm 13.3$ & 0.99 \\
$\quad$ & 19 & 22 & \\
$\quad \begin{array}{l}\text { Chronic lower abdominal } \\
\text { discomfort }\end{array}$ & 5 & $1 \mathrm{I}$ & 0.71 \\
$\quad$ Chronic constipation & 10 & 14 & 0.18 \\
$\quad \begin{array}{l}\text { Hematochezia } \\
\quad \text { Others }\end{array}$ & 25 & 16 & 0.13 \\
Patients education level, $\mathrm{n}$ & 7 & 3 & 0.13 \\
$\quad$ High/low & & & \\
\hline
\end{tabular}

which produce pain sensation and colonoscopy difficulties; minimizing inflation is an important part of the solutions. ${ }^{7}$ However, there is no study yet about the reliable water "inflation" level that should be used in water-assisted method for successful colonoscopy. A study, which compared warm water infusion and air insufflation for unsedated colonoscopy, used a water pump flow rate of $3.5 \mathrm{~mL} / \mathrm{s}(210 \mathrm{~mL} / \mathrm{min})$ and showed that warm water infusion did not decrease the number of patients requiring on-demand sedation. ${ }^{8}$ Another study also used JW-2 endoscope-connected water pump (similar to water pump used for LFR group in this study), in minimally sedated patients. ${ }^{9}$
There was a curiosity about how the water worked in the water immersion method colonoscopy and why it produced lower discomfort score and faster intubation time as shown in previous studies comparing water immersion and air insufflation in both sedated and unsedated patients. ${ }^{1-5}$ A study showed that warm or room temperature water did not make any difference and presumed the role of hydrostatic pressure. ${ }^{10}$ Our findings seem to support this opinion. The HFR water pump improved the performance of water immersion method colonoscopy and reduced the pain score. Based on our observation during the study, the HFR endoscope water pump infused much more water in a shorter period of time so that it produced rapid and stronger pressure to the colonic wall and dilated it moderately and only locally.

In this study, we did not measure the water volume after colonoscopy examination. The role of overall water volume itself is still unclear because the colon is a long hollow structure and the water only fills the local area of the flexible colonic lumen during examination. Hydrostatic pressure produced by the locally infused water may have a predominant role. It is different from the air insufflation in which the air will rapidly fill all parts of the colonic lumen. We infused the water only as needed and not continued infusion as water exchange method. It means the water was infused only when we found collapsed lumen of the colon or angulated colonic curve to cannulate. We infused the water only when 
Table 2 Effect of high and low flow rates on measured parameters

\begin{tabular}{|c|c|c|c|}
\hline \multirow[t]{2}{*}{ Measured parameters } & \multicolumn{2}{|c|}{ Endoscope water pump flow rates } & \multirow[t]{2}{*}{$p$-value } \\
\hline & High flow rates & Low flow rates & \\
\hline Time to pass rectosigmoid $(\min )^{\mathrm{a}}$, mean $\pm \mathrm{SD}$ & $3.6 \pm 2.2$ & $6.2 \pm 4.6$ & $<0.001$ \\
\hline Cecal intubation time $(\min )^{\mathrm{a}}$, mean $\pm \mathrm{SD}$ & $12.5 \pm 6.2$ & $16.3 \pm 7.3$ & 0.004 \\
\hline Cecal intubation rate ${ }^{\mathrm{b}}, \mathrm{n}(\%)$ & 58 of $66(87.9 \%)$ & 53 of $66(80.3 \%)$ & 0.34 \\
\hline Total colonoscopy time $(\mathrm{min})^{\mathrm{a}}$, mean $\pm \mathrm{SD}$ & $18.7 \pm 6.8$ & $21.8 \pm 8.6$ & 0.04 \\
\hline Pain score (VAS 0-10), mean \pm SD & $4.2 \pm 2.8$ & $5.3 \pm 2.6$ & 0.024 \\
\hline VAS score $<4.4$ (mild pain)", $n$ & 26 of $58(44.8 \%)$ & 19 of $53(35.8 \%)$ & 0.44 \\
\hline Willingness to repeat ${ }^{\mathrm{b}}, \mathrm{n}(\%)$ & 46 of $58(79.3 \%)$ & 37 of $53(69.8 \%)$ & 0.28 \\
\hline Redundancy but successful, $n$ & 14 & 15 & \\
\hline Time to pass rectosigmoid $(\mathrm{min})^{\mathrm{a}}$, mean $\pm \mathrm{SD}$ & $4.7 \pm 3.1$ & $10.4 \pm 7.2$ & 0.01 \\
\hline Cecal intubation time $(\min )^{\mathrm{a}}$, mean $\pm \mathrm{SD}$ & $17.6 \pm 6.5$ & $22.1 \pm 6.9$ & 0.087 \\
\hline Failure due to redundancy, $\mathrm{n}$ & 6 & 8 & \\
\hline Failure due to pain, $n$ & 2 & 5 & \\
\hline Constipation group, $\mathrm{n}$ & 9 & 10 & \\
\hline Time to pass rectosigmoid (min) ${ }^{\mathrm{a}}$, mean $\pm \mathrm{SD}$ & $3.7 \pm 2.7$ & $7.6 \pm 7.9$ & 0.17 \\
\hline Cecal intubation time $(\min )^{\mathrm{a}}$, mean $\pm \mathrm{SD}$ & $16.1 \pm 6.1$ & $17.9 \pm 7.67$ & 0.58 \\
\hline Non-constipation group, $\mathrm{n}$ & 49 & 43 & \\
\hline Time to pass rectosigmoid $(\mathrm{min})^{\mathrm{a}}$, mean $\pm \mathrm{SD}$ & $3.5 \pm 2.0$ & $6.2 \pm 3.9$ & $<0.001$ \\
\hline Cecal intubation time $(\min )^{\mathrm{a}}$, mean $\pm S D$ & $11.9 \pm 6.1$ & $15.9 \pm 7.2$ & 0.005 \\
\hline External abdominal compression, $\mathrm{n}$ & 0 of 66 & 0 of 66 & \\
\hline Patient position change, $n$ & 66 of 66 & 66 of 66 & \\
\hline
\end{tabular}

Notes: VAS score: I= no pain; I0= worst pain. aStudent's $t$-test. ${ }^{b}$ Chi-square/Fisher's exact test.

Abbreviation: VAS, visual analog scale.

we needed the water pressure to moderately dilate and then cannulate the colonic curves.

The HFR endoscope water pump machine used in this study was similar to the one used in our previous study (water immersion vs air insufflation). ${ }^{3}$ The mean VAS score of the treatment group was similar in the two studies (4.1 [in water vs air study] vs 4.2 [in this study]). Successful rectosigmoid cannulation is an important part of successful cecal intubation. This study also confirmed the need of HFRs of water for successful and less painful rectosigmoid cannulation during the water immersion method colonoscopy in unsedated patients. Higher water pressure produced by water flow from HFR endoscope-connected water pump in the rectosigmoid curve during water infusion and withdrawal simultaneously might play a role in this successful rectosigmoid cannulation. This maneuver straightened the angulated rectosigmoid segment and then facilitated cannulation of the sigmoid. High flow rates increased cecal intubation rate in colon redundant cases, but the increase was not significant. Our previous study ${ }^{3}$ showed that in the air insufflation group a cecal intubation rate of $89.5 \%$ was achieved with abdominal compression in difficult cases. Abdominal compression to reduce looping was not performed in this study to keep both unsedated groups comparable. Cecal intubation failed in 21 patients (total numbers of both groups) in the current study.
This contributed to the reduced overall cecal intubation rate (HFR vs LFR: $87.9 \%$ vs $80.3 \%$ ). The absence of abdominal compression might have contributed to the reduced cecal intubation rate in the current study. ${ }^{3}$

\section{Conclusion}

The HFRs of endoscope-connected water pump in the water immersion method of unsedated colonoscopy reduced the patients' pain sensation, time to pass rectosigmoid, and cecal intubation time.

\section{Acknowledgments}

We acknowledge the support from Ns Rofi'ah and Ns Lilik Azizah, the nurses of Sardjito General Hospital endoscopy room, for their active support during colonoscopy examinations. The abstract (Sa-1747) of this work has been presented at the Digestive Diseases Week, San Diego, CA, USA, May 22, 2016.

\section{Author contributions}

All authors contributed toward study concept and design, acquisition of data, data analysis and interpretation data, drafting and revising the paper, gave final approval of the version to be published, and agree to be accountable for all aspects of the work. Colonoscopy examinations were only performed by Putut Bayupurnama. 


\section{Disclosure}

The authors report no conflicts of interest in this work.

\section{References}

1. Leung FW. Methods of reducing discomfort during colonoscopy. Dig Dis Sci. 2008;53(6):1462-1467.

2. Leung FW, Harker JO, Jackson G, et al. A proof-of-principle, prospective, randomized, controlled trial demonstrating improved outcomes in scheduled unsedated colonoscopy by the water method. Gastrointest Endosc. 2010;72(4):693-700.

3. Bayupurnama P, Ratnasari N, Indrarti F, Triwikatmani C, Nurdjanah $\mathrm{S}$, Leung FW. The water method colonoscopy in routine unsedated colonoscopy examinations: a randomized controlled trial (RCT) in diagnostic cases in Indonesian patients. J Interv Gastroenterol. 2013;3(1): $12-17$.

4. Leung JW, Do LD, Siao-Selera RM, et al. Retrospective analysis showing the water method increased adenoma detection rate - a hypothesis generating observation. J Interv Gastroenterol. 2011;1(1):3-7.
5. Leung FW, Amato A, Ell C, et al. Water-aided colonoscopy: a systematic review. Gastrointest Endosc. 2012;76(3):657-666.

6. Cohen J. Statistical Power Analysis for the Behavioral Sciences. 2nd ed. Hillsdale, NJ: Erlbaum; 1988.

7. Loeve AJ, Fockens P, Breedveld P. Mechanical analysis of insertion problems and pain during colonoscopy: why highly skill-dependent colonoscopy routines are necessary in the first place.... and how they may be avoided. Can J Gastroenterol. 2013;27(5):293-302.

8. Radaelli F, Paggi S, Amato A, Terruzzi V. Warm water infusion versus insufflation for unsedated colonoscopy: a randomized, controlled trial. Gastrointest Endosc. 2010;72(4):701-709.

9. Hsieh YH, Tseng KC, Hsieh JJ, Tseng CW, Hung TH, Leung FW. Feasibility of colonoscopy with water infusion in minimally sedated patient in an Asian community settings. J Interv Gastroenterol. 2011;1(4):185-190.

10. Lee BY, Katon R, Herzig D, Fennerty MB. Warm water infusion during sedated colonoscopy does not decrease amount of sedation medication used. Gastrointest Endosc. 2012;76:1182-1187.

11. Jensen MP, Chen C, Brugger AM. Interpretation of visual analog scale ratings and change scores: a reanalysis of two clinical trials of postoperative pain. J Pain. 2003;4(7):407-414.
Clinical and Experimental Gastroenterology

\section{Publish your work in this journal}

Clinical and Experimental Gastroenterology is an international, peerreviewed, open access, online journal publishing original research, reports, editorials, reviews and commentaries on all aspects of gastroenterology in the clinic and laboratory. This journal is included on PubMed. The manuscript management system is completely online

\section{Dovepress}

and includes a very quick and fair peer-review system, which is all easy to use. Visit http://www.dovepress.com/testimonials.php to read real quotes from published authors. 